\title{
Novel Otolaryngology Simulation for the Management of Emergent Oropharyngeal Hemorrhage
}

\author{
Joshua Feintuch, BA ${ }^{1}$; Jeremy Feintuch, BA ${ }^{1}$; Emily Kaplan MPA, EMTP2; \\ Merona Hollingsworth, $\mathrm{BS}^{3}$; Christina Yang, MD; Marc J. Gibber, $\mathrm{MD}^{4 *}$
}

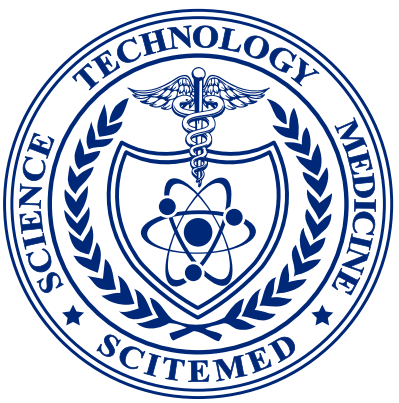

${ }^{1}$ New York University School of Medicine, New York, New York, USA

${ }^{2}$ Montefiore-Einstein Center for Innovation in Simulation, Bronx, New York, USA

${ }^{3}$ Mary and Michael Jaharis Simulation Center, College of Physicians and Surgeons, Columbia University, New York, New York, USA

${ }^{4}$ Department of Otorhinolaryngology - Head \& Neck Surgery, Albert Einstein College of Medicine, Bronx, New York, USA

\begin{abstract}
Introduction: Oropharyngeal hemorrhage is a rare but life-threatening complication of oropharyngeal tumors. Bleeding episodes such as these can quickly lead to airway obstruction, aspiration and can result in asphyxiation. Nascent otolaryngology residents who have recently graduated medical school are expected to manage this situation with scant amount of prior experience. Simulation offers the unique opportunity to learn procedural skills to a resident/trainee in a safe, controlled environment designed to have specific, obtainable educational goals without any risk to the patient.

Methods: In this study, we created a simulation scenario in which junior otolaryngology residents learned to properly and safely manage a patient with an oropharyngeal bleed while also learning to properly interact and communicate with fellow healthcare providers in a tense, emergent situation.

Results: A 5-point Likert scale survey was utilized to assess realism and benefit from the simulation. An average score of 4.7 points was obtained for this simulation.

Conclusion: We developed an effective and realistic oropharyngeal bleeding mass scenario that was well received by participants in preparing them for real life scenarios.
\end{abstract}

\section{Introduction}

Oropharyngeal hemorrhage is a rare but life-threatening complication of oropharyngeal tumors [1]. They can occur quickly, and with or without stimulation of the tumor. Bleeding episodes such as these can quickly lead to airway obstruction, aspiration and can result in asphyxiation [1]. Oropharyngeal bleeds are associated with these dangerous outcomes and also have a high mortality rate because safe management of these cases can be rather complex [1]. Nascent otolaryngology residents who have recently graduated medical school are "expected to triage and manage airway [and] bleeding with little prior experience [2]." Further, due to the emergent nature of these bleeds, the approach to rapid patient stabilization likely involves providers from different specialties working side by side to manage this life-threatening condition. This can make for a stressful setting in which conflicting medical opinions pertaining to management may arise. With all of this in mind, we created a simulation scenario in which our junior residents learned to properly and safely manage a patient with an oropharyngeal bleed while also learning to properly interact and communicate with fellow healthcare providers in a tense, emergent situation. The goals of the study were to apply airway management and leadership skills in the context of a clinical team as well as to identify and adapt to clinical changes in real time.

\section{Methods}

This scenario was designed for the training of first year residents (interns), however it can be used for residents at any level of training. In order to benefit most from this scenario, the participating intern/resident should have a background of the basic anatomy of the oropharynx pri- or to running through the simulation. Table 1 shows a list of equipment needed for both the mannequin setup and for the oropharyngeal bleed simulation.

\begin{tabular}{|c|c|}
\hline Mannequin Setup & Scenario Management \\
\hline Laerdal ALS Mannequin® & Mouth guards \\
\hline Simulated patient monitor & $\begin{array}{l}\text { Mac blade, laryngoscope } \\
\text { handle, extra batteries }\end{array}$ \\
\hline Instructor computer & Fiberoptic scope \\
\hline Link box & Camera and tower \\
\hline $\begin{array}{l}\text { External compressor for chest rise } \\
\text { and fall }\end{array}$ & Portable light source \\
\hline $3 \mathrm{~L}$ bag of pre-Mixed blood per learner & Trachestomy tray \\
\hline Administrator extension set $10 \mathrm{gtt} / \mathrm{ml}$ & Tracheostomy tubes \\
\hline 30" IV extension tubing & Scalpels \\
\hline $\begin{array}{l}\text { Absorbent disposable fluff underpads } \\
\text { (chucks) }\end{array}$ & Headlight \\
\hline \multicolumn{2}{|l|}{$6.5 \mathrm{ETT}$ tube } \\
\hline \multicolumn{2}{|l|}{ HY-tape® } \\
\hline \multicolumn{2}{|l|}{$60 c c$ syringe } \\
\hline \multicolumn{2}{|l|}{ 3-way stopcock } \\
\hline Magill forceps & \\
\hline
\end{tabular}




\section{Mannequin Setup}

Our oropharyngeal tumor simulator was created to train our Otolaryngology junior residents on management of oropharyngeal bleeding. Realism is enhanced through the specific, novel, selection of the manikin for modification. We used the electronic simulator Laerdal ALS Mannequin. The mannequin breathes, has lung sounds, heart sounds, talks and has the capacity to display vital signs. To set up for this simulation, the abdominal bag was removed and padded with absorbent disposable fluff underpads (chucks) to absorb any residual fluids that ran along the pharynx into the mannequin (Figure 1). The chest skin was also removed, and the internal mechanics were covered with a towel and chucks (absorbable side up) to capture any residual fluids. We then disconnected the esophagus from the mannequin's abdomen (Figure 2) and placed the bottom of the esophagus into a plastic bag to prevent fluid from damaging the innards of the mannequin. IV tubing, attached to a pre-mixed $3 \mathrm{~L}$ bag of artificial blood, and extension tubing, was then threaded through the esophagus into the oropharynx (Figure 3). The cuff of a 6.5 ET tube was inflated, and the ET tube tip was cut off. A portion of the proximal end of the ETT tube was also removed with a scissor. The inflated balloon was then covered with HY-Tape ${ }^{\circledR}$ to make the mass look more realistic (Figure 4). The IV tubing from the oropharynx (that was threaded up the esophagus) was then pulled up using Magill forceps and threaded through the inverted ET tube (Figure 5), letting the opening of IV tubing to sit right at the inflated balloon of the ET tube. The inverted tube, with the IV tubing still inside was then placed into the oropharynx using Magill forceps, allowing the balloon to sit in the oropharynx (Figure 6), and the superior part of the tube to go down the pharynx.

\section{Bleeding}

In order to facilitate bleeding (Figure 7), we used two different, but equally effective techniques.

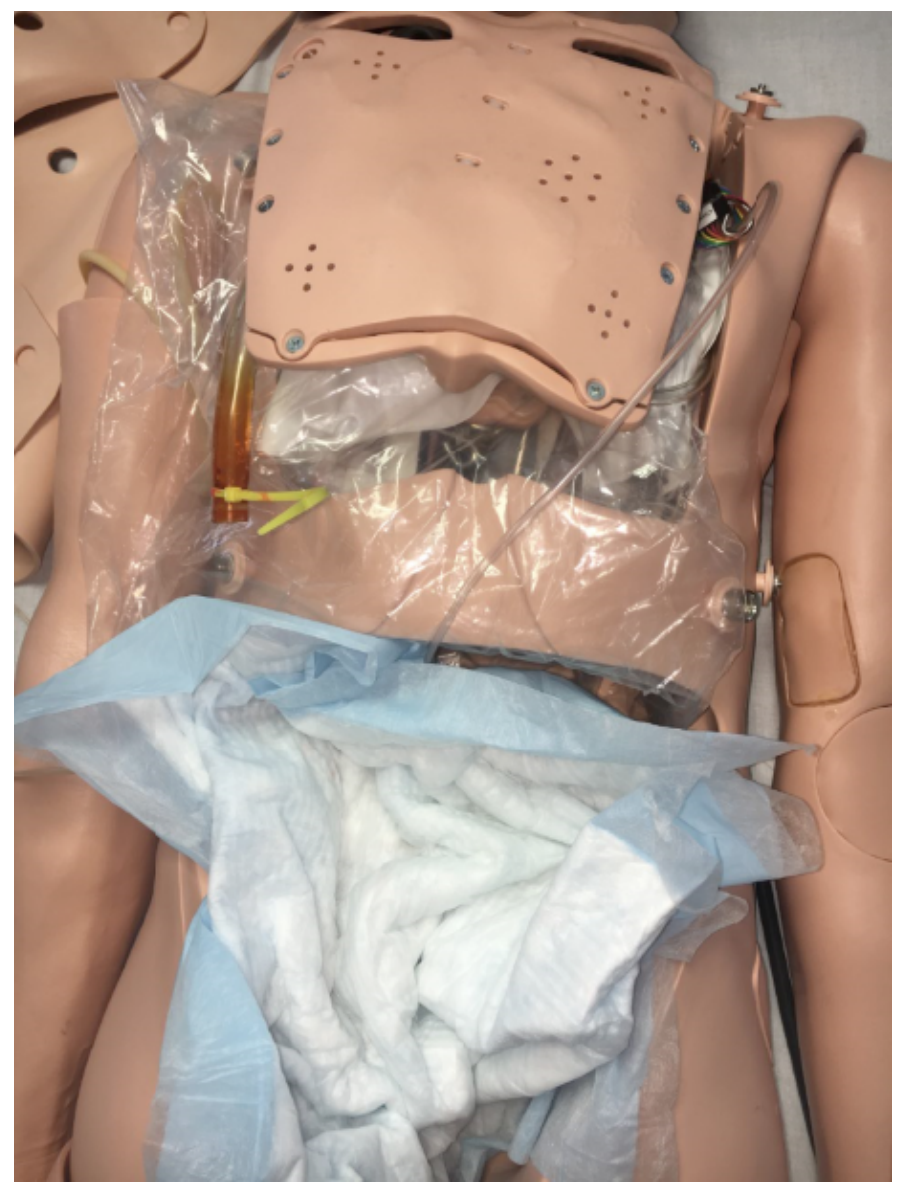

Figure 1. Preparation of the mannequin for simulation step 1.
Version 1

An Alaris 8015 pump tubing is connected to the extension tubing with a $3 \mathrm{~L}$ bag of pre-mixed artificial blood. To express minimal continual bloodflow, the pump was set to express $500 \mathrm{ml}$ in 10 minutes. Greater blood flow is achieved by increasing the rate of the pump. Up to 1 liter of blood should be aimed to be expressed per learner. The pump is positioned behind the mannequin. This version requires manual changes of pump setting to increase blood flow.

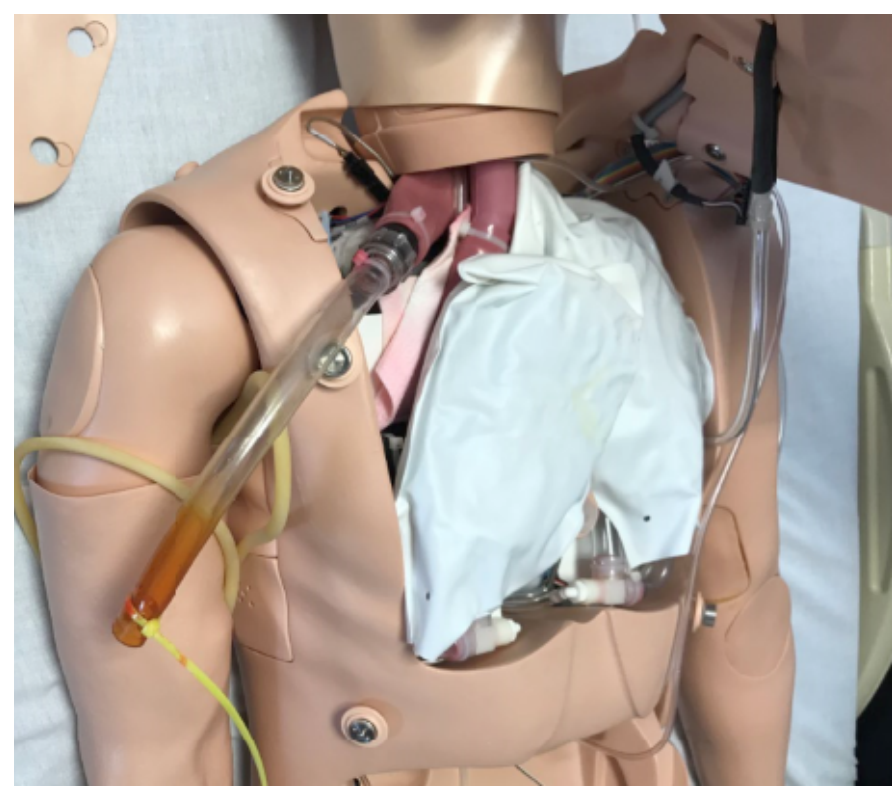

Figure 2. Preparation of the mannequin for simulation step 2.

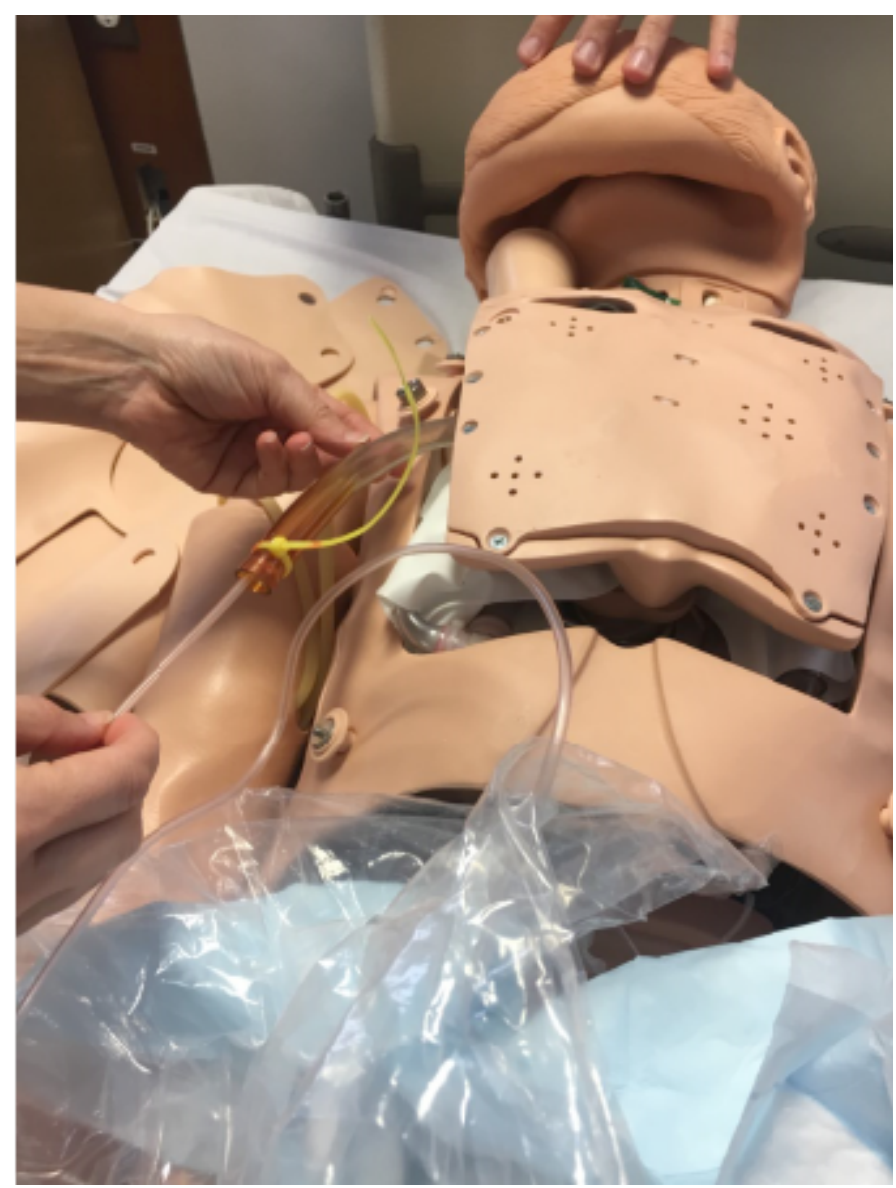

Figure 3. Intravenous tube placement. 


\section{IDEA AND INNOVATION}

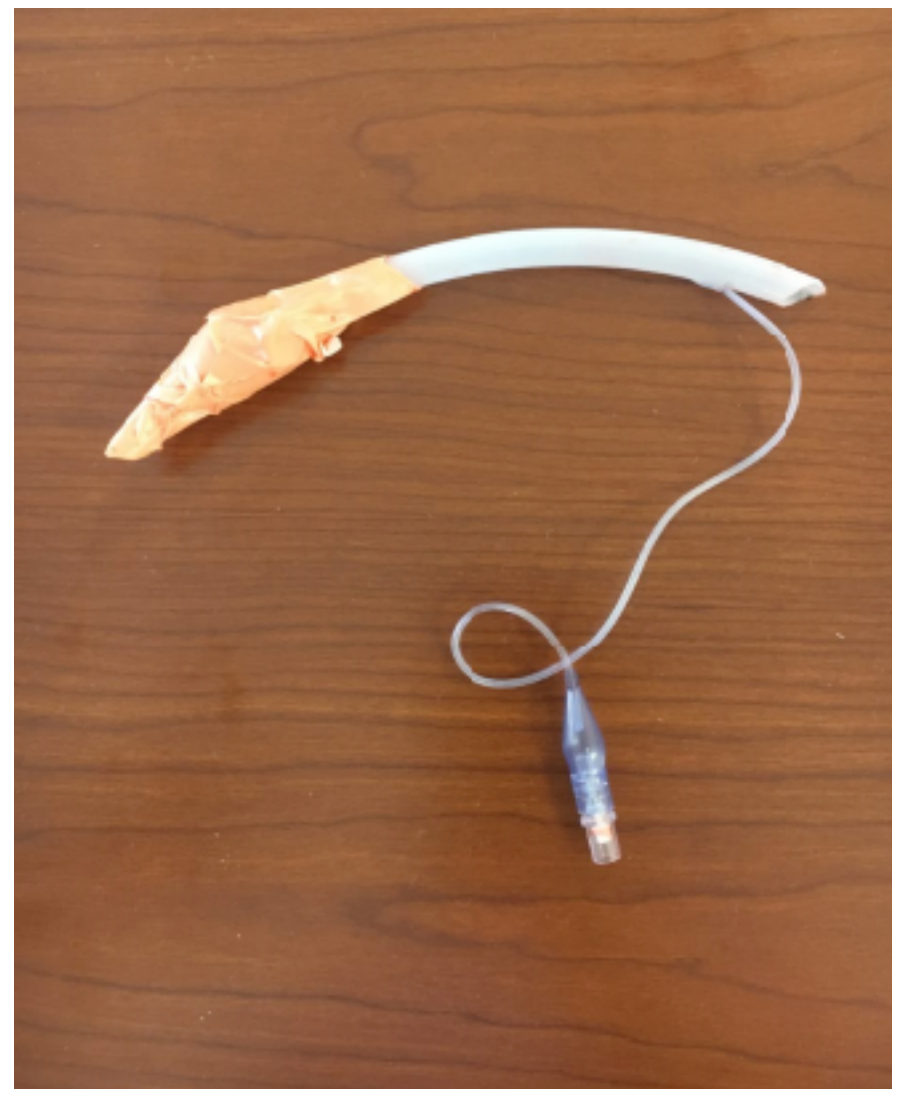

Figure 4. Construction of the oropharyngeal mass.

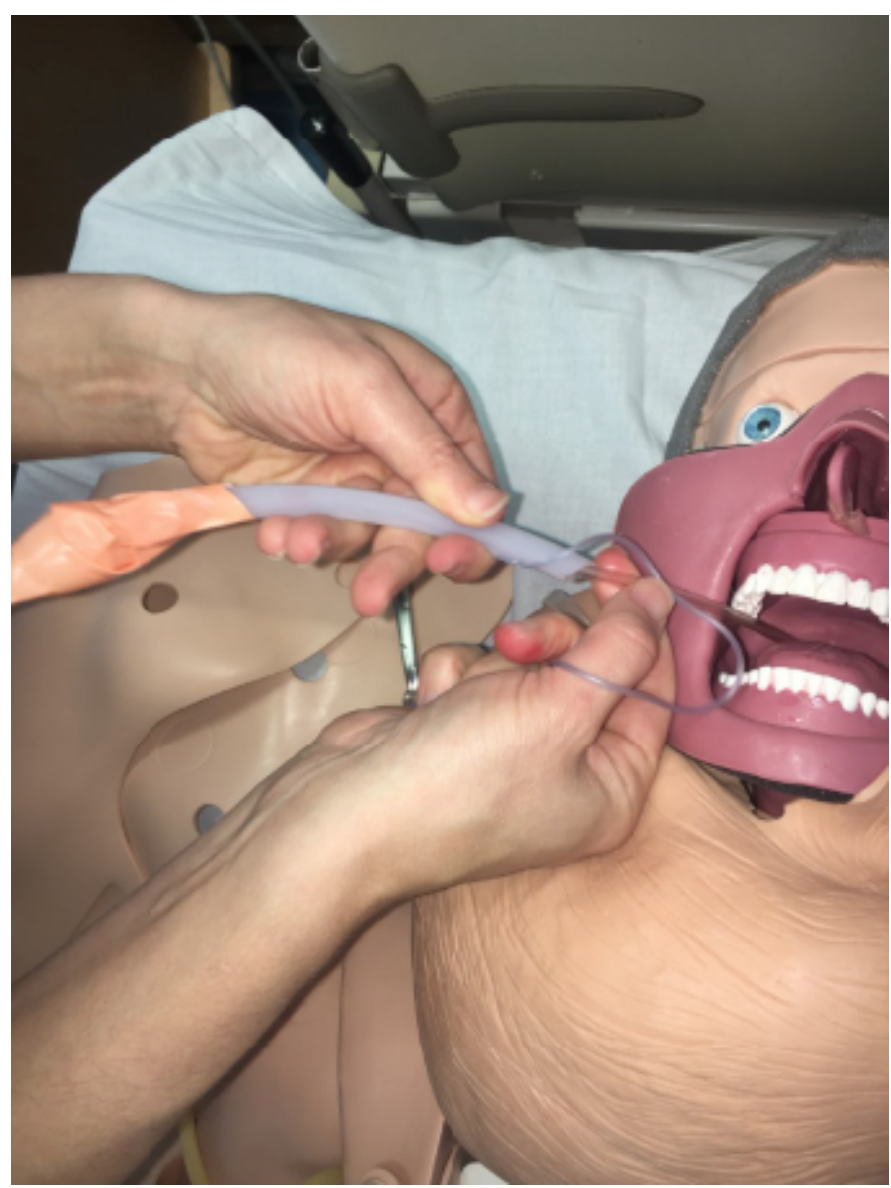

Figure 5. Preparation of the oropharyngeal mass for bleeding.

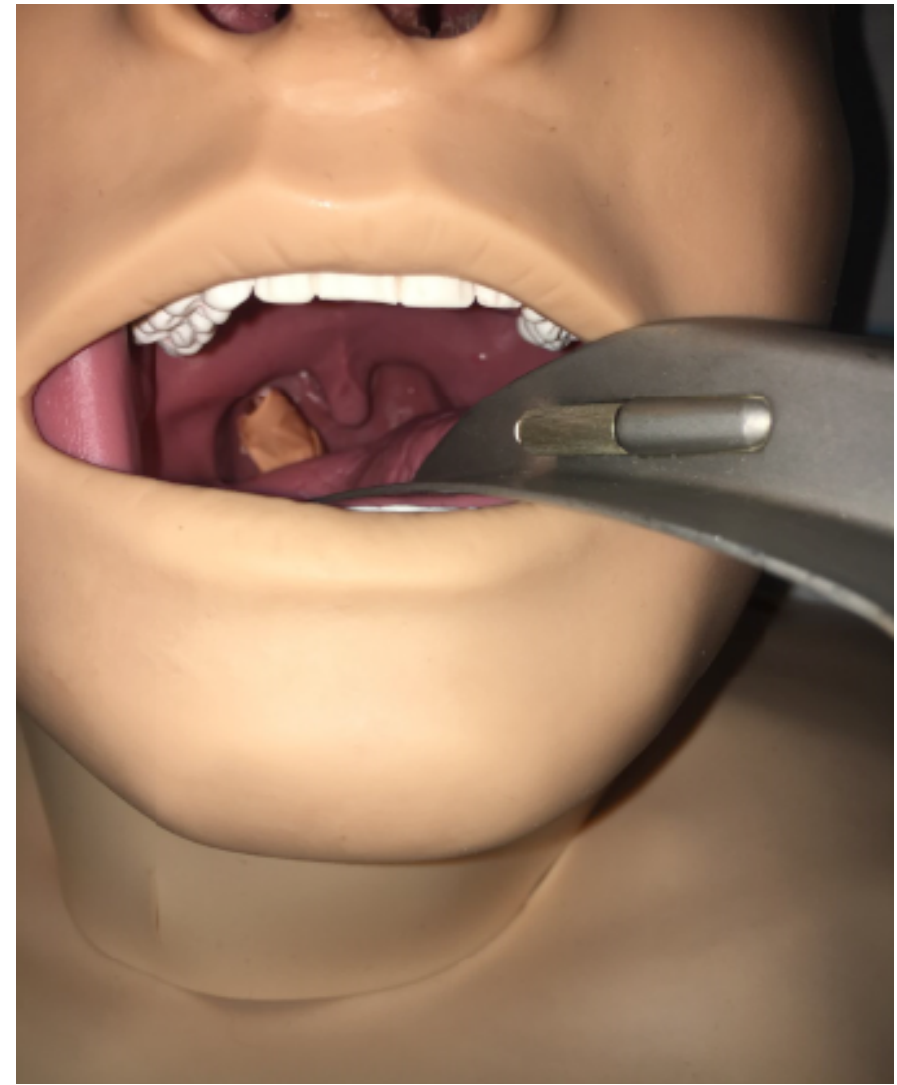

Figure 6. Placement of the oropharyngeal mass.

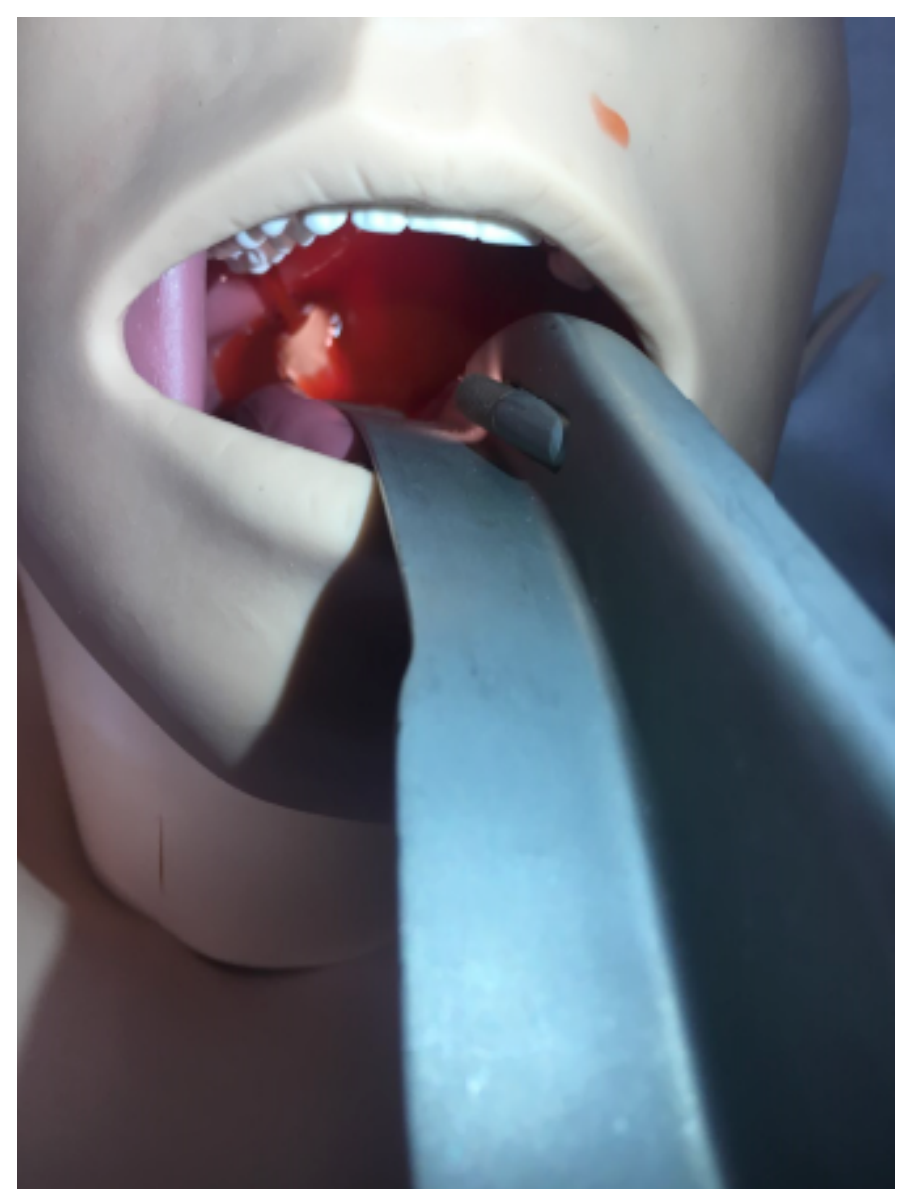

Figure 7. Bleeding from the oropharyngeal mass. 


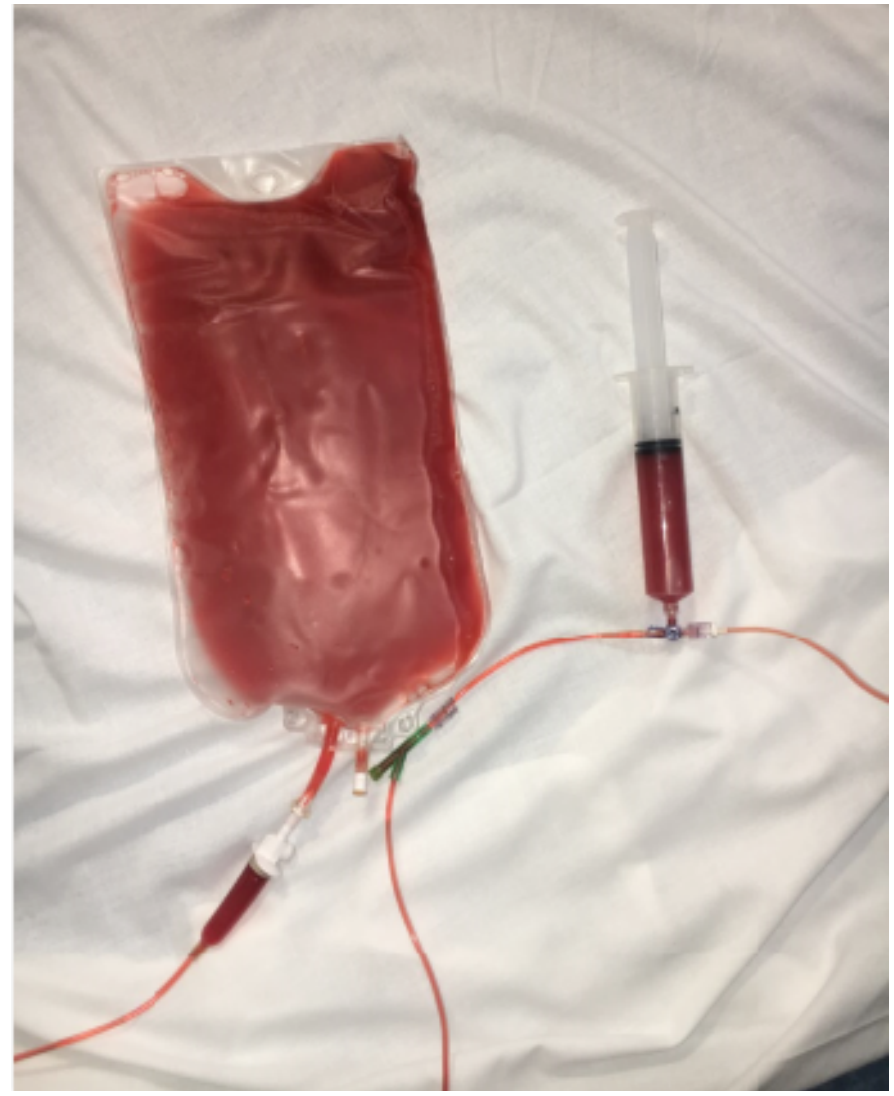

Figure 8. Bleeding equipment setup: version 2.

Version 2

To express greater blood volume and force associated with emergent bleeding cases, a manual hand pump is utilized. A three-way stop-cock is attached to the extension IV tubing. A 60 CC syringe is connected to one port. The remaining port is attached to a pre-mixed $3 \mathrm{~L}$ bag of blood via an Administrator Extension set and IV tubing (Figure 8). The Simulation Technician is positioned behind the bed, out of the learner's line of sight. Using the 60 CC syringe and three way stop cock, blood is drawn up into the syringe from the 3-liter reservoir bag. After the syringe is completely full, the stopcock is then switched to allow blood to be expressed from the syringe into the patient's oropharynx. Blood is then expressed from the syringe, at the desired rate, to cause oropharyngeal bleeding. The process is repeated continuously throughout the scenario. After the mannequin setup is complete, the learner can then manage the oropharyngeal bleeding as directed by the instructor/scenario.

\section{Scenario}

The intern/learner is paged to the intensive care unit(ICU) for a 69-year-old male with history of oropharyngeal cancer complaining of oral bleeding. The ICU attending is at the bedside. Table 2 shows the vital sign setting.

The intern/learner assesses the patient who complains of difficulty breathing as he/she is coughing up blood. The ICU attending urges the intern/learner to help the patient. The intern/learner should first attempt to suction the airway and use a fiber optic scope to establish the source of the bleed. If scoped correctly, the source of the bleed should be identified as the bleeding mass in the posterior oropharynx. As more time passes, the patient's oxygen saturation continues to drop, and he becomes increasingly tachycardic. Seeing the dropping oxygen saturation, the ICU attending questions the intern/learner if an orotracheal intubation could be a good treatment option for this patient. The intern/learner should explain to the ICU attending the risks associated with sedating a patient with an oropharyngeal mass. As the patient's oxygen saturation continues to drop, the intern/learner should assess the feasibility and safety for an attempted nasotracheal intubation. If the intern/learner deems a

\section{Table 2. Vital Signs Setup}

\begin{tabular}{l|l|}
\hline General & $\begin{array}{l}\text { Patient is sitting in bed at } 45 \text { degrees, with blood } \\
\text { dripping from mouth. Patient is in mild distress }\end{array}$ \\
\hline $\begin{array}{l}\text { Head, Eyes, Ears, } \\
\text { Nose, Throat }\end{array}$ & Active bleeding from oropharynx \\
\hline Pulmonary & Clear to auscultation bilaterally \\
\hline Cardiovascular & Normal S1/S2. No murmurs \\
\hline Extremities & No cyanosis or clubbing noted \\
\hline Heart Rate & 118 Beats Per Minute \\
\hline Blood Pressure & $165 / 100$ mmHg \\
\hline Respiratory Rate & 44 respirations per minute \\
\hline Temperature & $39.3^{\circ} \mathrm{C}$ \\
\hline Oxygen Saturation & Starts at $93 \% \mathrm{O}_{2}$, rapidly dropping over 2 minutes \\
\hline
\end{tabular}

nasotracheal intubation safe, he/she should attempt to perform one. If successfully placed, the patient's oxygen saturation should increase, and vitals should stabilize.

If the intern/learner is not able to perform a nasotracheal intubation, or if the patient destabilizes at any point in the scenario, the intern/leaner should perform a cricothyroidotomy. If the intern/learner is unsuccessful in managing the scenario, the patient will continue to decompensate. If at any point, the intern/learner sedates the patient, the patient should decompensate. At the conclusion of the scenario, participants were then asked to fill out a 5-point Likert score to assess realism and perceived benefit from the simulation.

To ensure benefit from this scenario, a pre-training and post-training assessment can be used as well.

\section{Results}

Over the last 2 years, 8 interns completed this simulation. A 5-point Likert scale survey was utilized to assess resident perceived realism and benefit from this simulation. An average score of 4.7 points was obtained for this simulation.

\section{Discussion}

The expeditious transition from a senior medical student to a junior resident can be a daunting, and overwhelming experience. Coming from a sheltered and protected environment to one that is fraught with patient encounters, situation- based decisions and technical skills can cause much stress for a new intern [3]. In addition to the stress put on the resident, evidence has emerged that there is more incidence of physician error causing patient harm in the beginning of residency [4]. This situation can be made even worse when entering a surgical and a procedure-laden subspecialty such as otolaryngology, where the technical skills are so specialized that some of them are not taught in medical school [5]. To mitigate this issue, attempts have been made, through simulation and boot camp training, to equip these novice residents with the skills needed to succeed in their new role.

Simulation offers the opportunity to learn procedural and interviewing skills to a resident/trainee in a safe, controlled environment that is designed to have specific educational opportunities without serious risk to the patient [3,6-11]. Just as it applies to the military, boot camp style learning emphasizes teaching novices the basic skills necessary to properly function in a real-world scenario. In otolaryngology, the ultimate goal is to transition "undifferentiated senior medical students to dedicated otolaryngology residents [3]." With the advent of duty hour restrictions and resource limitations, training a resident in a shorter period of time and in a more modifiable environment is being more heavily favored than traditional teaching of only experiencing a medical emergency in a real-life situation $[2,3,7,12,13]$. By putting these skills into a boot camp style course, residents are given the opportunity to participate in intense-style training while still being taught in a safe, simulated environment. 
Time and time again, simulation-based training has shown its effectiveness in the medical field, and specifically in the field of otolaryngology [14-16]. A study in 2015 by Chin et al. found that "an otolaryngology boot camp gives residents the chance to learn and practice emergency skills before encountering the emergencies in everyday practice. Their confidence in multiple skill sets was significantly improved after the boot camp [7]." Other studies have also shown similar results in medicine and the field of otolaryngology $[17,18]$. All of these studies have consistently shown that through simulation and boot camp training, residents began developing the appropriate knowledge, skill set and self-confidence $[2,7]$ needed to succeed during residency and, more importantly, that these skills transferred to real clinical situations/procedures with real patients.

Due to the proven success of simulation-based learning, we have created a scenario in which our residents can practice how to properly manage an oropharyngeal bleed. Vascular erosion, causing a hemorrhagic episode, can occur in all patients with advanced-stage tumors, recurrent tumors, infection and pharyngocutaneous fistulas [1,19]. Additionally, when chemotherapy and radiation are used in conjunction, without surgical intervention, secondary adverse effects can arise, including "erosion of skin and mucosa.... premature atherosclerosis with stenosis and weakening of arterial walls due to adventitial fibrosis, fragmentation of elastic filaments, and destruction of vasa vasorum. Following chemoradiation, therapy, spontaneous hemorrhage can result as a consequence of weakened arterial walls [1]." This complication, especially in tumors arising from the oropharynx can be particularly devastating.

These emergent situations must be recognized and cared for quickly to prevent blood loss, aspiration and/or asphyxiation. However, caution must be used when managing a patient like this, as a wrong step can put the patient at serious risk. A patient with a bleeding oropharyngeal mass who loses consciousness or is anesthetized, may lose the ability to protect his/her own airway and the bleeding may continue to flow distally, causing asphyxiation [20]. Further, endotracheal intubation can irritate and stimulate the bleeding lesion, thus exacerbating the bleeding and making airway management even more difficult [20]. With these complications in mind, nasotracheal intubation is seen as the safest and most effective way of securing an airway in these patients. Our simulation allows our residents to systematically work through the critical decision-making process in a safe environment, in order to acquire the knowledge as well as the manual dexterity to properly manage these patients.

As with other medical emergencies, managing an oropharyngeal bleed can be stressful. Working with healthcare providers of a different specialty can sometimes add to the stress, as there may be differing opinions related to patient management. Junior residents can be more susceptible to these stressors, as they may lack the experience and confidence needed to make a decision in the face of conflict. While the leader of the medical team is ultimately in charge of the decision-making during a medical emergency, there may be times when a trainee from one specialty may not agree with a treatment decision made by an attending of a different specialty. In this situation, we want to foster professionalism, collaboration, leadership and communication skills between both medical providers from different training backgrounds. In a study performed by Belyansky et al., it was found that " $74-78 \%$ of trainees and attendings recalled an incident where the trainee spoke up and prevented an adverse event. While all attendings in this study reported that they encourage residents to question their intraoperative decision making, only $55 \%$ of residents agreed [21]." By being encouraged to voice concerns during an emergency, trainees can act as partners in the reduction of possible medical errors. Further, in a literature review by Ignacio et al., it was found that "excessive stress and/or anxiety in the clinical setting have been shown to affect performance and could compromise patient outcomes [22]." In and out of the field of medicine, studies have "suggested that stress training showed an improving trend in performance.... [and was a] valuable strategy for enhancing... thought process and improving... performance in communication skills [22]." By presenting the junior residents with a stressful situation in which an attending suggests a management option that might not be appropriate for the patient, the residents learn how to properly and respectfully suggest an alternate treatment approach, while also learning the technical skills needed to properly care for such a patient. This provides the resident with the tools necessary to deal with such a situation, when it is appropriate, during residency and beyond. Using this simulation, the learner is encouraged to move from comprehension and application to synthesis and evaluation.

The novelty of this scenario comes from both the setup of the mannequin, and the use of the mannequin with the designed scenario. By using this simulation, the intern/learner learns how to both utilize the treatment algorithm for a bleeding oropharyngeal mass and work with members of medical teams composed of members from different specialties and experience levels. This simulation facilitates the development of technical, knowledge-based and interpersonal skills all within a succinct and collaborative educational environment.

\section{Conclusion}

Using a safe and controlled simulation environment, we were able to develop an effective and realistic oropharyngeal bleeding mass scenario that was well received by participants.

\author{
Article Information \\ *Correspondence: Marc J. Gibber, MD \\ Department of Otorhinolaryngology - Head \& Neck Surgery, Albert \\ Einstein College of Medicine, Bronx, New York, USA. \\ Email: Mgibber@montefiore.org
}

Received: May 09,2018; Accepted: Jun. 20,2018; Published: Jul. 13, 2018

\section{DOI: $10.24983 /$ scitemed.aohns.2018.00068}

Copyright $(2018$ The Author (s). This is an open-access article distributed under the terms of the Creative Commons Attribution 4.0 International License (CC-BY).

\section{Funding: None}

\section{Conflict of Interest: None}

\section{Keywords}

Hemorrhage; oropharyngeal; otolaryngology; simulation; training.

\section{References}

1. Self EM, Bumpous J, Ziegler C, Wilson L, Potts K. Risk factors for hemorrhage after chemoradiation for oropharyngeal squamous cell carcinoma. JAMA Otolaryngol Head Neck Surg 2013;139(4):356-361.

2. Malekzadeh S, Malloy KM, Chu EE, Tompkins J, Battista A, Deutsch ES. ORL emergencies boot camp: using simulation to onboard residents. Laryngoscope 2011;121(10):2114-2121.

3. Yeh DH, Fung K, Malekzadeh S. Boot camps: preparing for residency. Otolaryngol Clin North Am 2017;50(5):1003-1013.

4. Young JQ, Ranji SR, Wachter RM, Lee CM, Niehaus B, Auerbach AD. "July effect": impact of the academic year-end changeover on patient outcomes: a systematic review. Ann Intern Med 2011;155(5):309-315.

5. Fung K. Otolaryngology-head and neck surgery in undergraduate medical education: advances and innovations. Laryngoscope 2015;125(Suppl 2):S1-14.

6. Kneebone RL, Scott W, Darzi A, Horrocks M. Simulation and clinical practice: strengthening the relationship. Med Educ 2004;38(10):10951102.

7. Chin CJ, Chin CA, Roth K, Rotenberg BW, Fung K. Simulation-based otolaryngology - head and neck surgery boot camp: 'how I do it'. $J$ Laryngol Otol 2016;130(3):284-290.

8. Langhan TS, Rigby IJ, Walker IW, Howes D, Donnon T, Lord JA. Simulation-based training in critical resuscitation procedures improves residents' competence. CJEM 2009;11(6):535-539. 


\section{IDEA AND INNOVATION}

9. Ziv A, Wolpe PR, Small SD, Glick S. Simulation-based medical education: an ethical imperative. Acad Med 2003;78(8):783-788.

10. Deutsch ES. High-fidelity patient simulation mannequins to facilitate aerodigestive endoscopy training. Arch Otolaryngol Head Neck Surg 2008;134(6):625-629.

11. Lin HL, Chen CW, Lee WC, et al. Effects of the Emergency Trauma Training Course on the confidence of final-year medical students dealing with trauma patients. Kaohsiung J Med Sci 2009;25(1):10-15.

12. Deutsch ES, Wiet GJ, Seidman M, Hussey HM, Malekzadeh S, Fried MP. Simulation activity in otolaryngology residencies. Otolaryngol Head Neck Surg 2015;153(2):193-201.

13. Lee AY, Fried MP, Gibber M. Improving rhinology skills with simulation. Otolaryngol Clin North Am 2017;50(5):893-901.

14. Fried MP, Sadoughi B, Gibber MJ, et al. From virtual reality to the operating room: the endoscopic sinus surgery simulator experiment. Otolaryngol Head Neck Surg 2010;142(2):202-207.

15. Ossowski KL, Rhee DC, Rubinstein EN, Ferguson BJ. Efficacy of sinonasal simulator in teaching endoscopic nasal skills. Laryngoscope 2008;118(8):1482-1485.
16. Smith ME, Trinidade A, Tysome JR. The ENT boot camp: an effective training method for ENT induction. Clin Otolaryngol 2016;41(4):421424.

17. Wiet GJ, Stredney D, Kerwin T, et al. Virtual temporal bone dissection system: OSU virtual temporal bone system: development and testing. Laryngoscope 2012;122(Suppl 1):S1-12.

18. McGaghie WC, Issenberg SB, Barsuk JH, Wayne DB. A critical review of simulation-based mastery learning with translational outcomes. Med Educ. 2014;48(4):375-385.

19. Turner $L$, Zitsch $R$, 3rd. Waldeyer's ring lymphoma presenting as massive oropharyngeal hemorrhage. Mo Med 2000;97(2):63-65.

20. Kim KN, Lee HJ, Choi HI, Kim DW. Airway management in patient with continuous bleeding lesion of the trachea: a case report. Korean J Anesthesiol 2015;68(4):407-410.

21. Belyansky I, Martin TR, Prabhu AS, et al. Poor resident-attending intraoperative communication may compromise patient safety. J Surg Res 2011;171(2): 386-394.

22. Ignacio J DD, Scherpbier A, Rethans J, Chan S, Liaw S. Stress and anxiety management strategies in health professions' simulation training: a review of literature. BMJ 2016;2:40-46. 